$15^{\text {th }}$ International Conference on

AEROSPACE SCIENCES \& AVIATION TECHNOLOGY,

$\boldsymbol{A S A T}$ - 15 - May 28 - 30, 2013, Email: asat@mtc.edu.eg,

Military Technical College, Kobry Elkobbah, Cairo, Egypt,

Tel: +(202) 24025292-24036138, Fax: +(202) 22621908

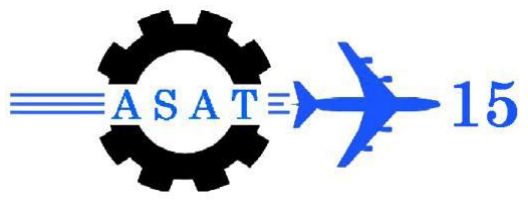

\title{
Development of an In-Door Tire Soil Bin Testing Facility Experimental Setup
}

\author{
A. Hendy ${ }^{*}$, S. Hegazy ${ }^{\dagger}$, M. A. Emam ${ }^{\ddagger}$ and Y. Hendawy ${ }^{\S}$
}

\begin{abstract}
The field testing may give the real conditions, but the uncontrolled environment may affect the results. In a soil bin, all driving conditions are controlled. Therefore a scaled soil bin was designed and established at MTC. The single wheel tester concludes the dynamic weight equal to that measured statically. Using an indoor soil bin, and measuring sensors the instantaneous wheel speed representing the theoretical speed and free wheel speed representing the actual speed were measured and recorded. Using the signals from two speed sensors, the instantaneous wheel slip is calculated. Also the dynamic sinkage due to wheel motion is measured using ultrasonic sensor. This paper presents a detailed experimental measuring of instantaneous wheel slip and dynamic sinkage on two surfaces; soft dry sand and hard surface. A theoretical control algorithm was developed and implemented. The control system using rotary valve and pressure sensor to control the tire pressure (inflation/deflation) based on the wheel slip ratio and dynamic sinkage.
\end{abstract}

Keywords: Indoor soil bin, tire inflation-deflation, slip ratio, dynamic sinkage.

\section{Introduction}

Many features have been incorporated to increase the performance of off-road vehicles; but the tire remains the most important parameter. There have been intensive research efforts to obtain a better understanding of the vehicle system due to the complex problems of interaction between the running devices (wheel, track, etc.) and various type conditions of terrain surfaces.

Traction performance for off road vehicles has been a challenging problem for many engineers. The soil-tire interface is responsible for about 20 to $55 \%$ of the losses of vehicle power, a factor that severely affects the amount of fuel used in drawbar implement applications [1]. In many studies, various testers, tire configurations and soil environments are the parameters that have been conducted. The tire performance was tested, using experimental methods. The tests may be conducted either on soil bin found in indoor testing facilities or by performing the real field testing. Soil bins, where the soil was brought to the tester, have been used to acquire a significant amount of data [2]. Onwualu [3] developed and used soil bins to study basic soil mechanics. This experience with small soil bins had led to the suggestion for the large soil bins facility. About 36 different facilities in 12 countries had 90 soil bins constructed [4]. There may have been about 150 soil bins in use around the world with only several new soil bins built since 1983 [3, 5].

\footnotetext{
*Egyptian Armed Forces, adelhendi@ hotmail.com .

$\dagger$ Egyptian Armed Forces.

Helwan University, Egypt.

${ }^{\S}$ Higher Technological Institute, 10th of Ramadan City, Egypt.
} 
Usually, the soil parameters in soil bins such as variation of cone index and soil compaction level are more constant [6]. Generally, a soil bin facility consists of soil bin, tool carriage, drive system, instrumentation and data acquisition systems. Soil bins are grouped into two design classes. One class of soil bin consists of straight or circular rails, movable soil bin in which the tested tool remains stationary. Another class involves fixed soil bin with a carriage that travels over the soil. The advantages of soil bin are well described by ASAE [7]. This experience with small soil bins had led to the suggestion for the large soil bin and many further tests [8].

\section{Single Wheel Tester Facility}

This section describes the construction of soil bin, moving carriage assembly (Single Wheel Tester, SWT) and measuring instruments.

\subsection{Design of Soil Bin}

The soil bin was designed from wood and supported with iron frame as shown in Fig. 1. Overall dimensions are $6 \mathrm{~m} \times 40 \mathrm{~cm} \times 25 \mathrm{~cm}$. It's length was selected to verify the tested tire with $25 \mathrm{~cm}$ diameter. It was provided with two metals $\mathrm{T}$ section beams over bin wall as two side rails, mounted along the wood bin length. The side rails were used to facilitate movement of the towing carriage as well as soil processing trolley over the soil bin. The bin was filled with the locally available sandy soil.

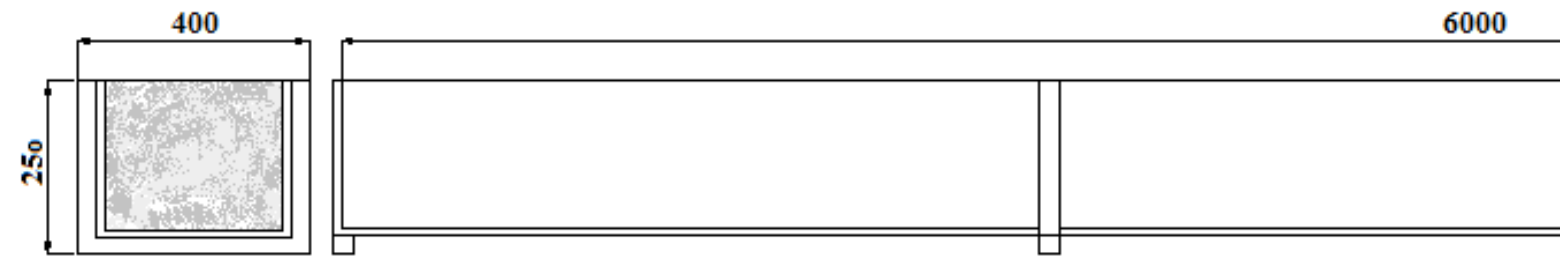

Fig. 1. Soil bin frame dimensions [mm]

\subsection{Single Wheel Tester Assembly}

The single wheel tester assembly consists of an upper plate, frame and linkage. The tested tire was mounted on the frame. The four bar parallel linkage system provided free vertical movement of the trolley and helped in transferring the normal load of the tester solely on the wheel. An induction motor of $1.5 \mathrm{~kW}, 3$-phase, was connected with speed controller to control the output speeds. The driving torque was transmitted via chain to the wheel. The used motor was mounted on the towing carriage and has a gearbox reduction ratio 7.8 . The second reduction was implemented by sprocket and chain drive arrangement (2.86:1). The tested tire was mounted on the output shaft of the gear reduction unit through a chain gear. The constructional details are shown in Fig 2 and Fig. 3.

Fig. 3.

\section{Measuring Instruments}

The measuring instruments include; the wheel speed sensor and free wheel speed sensor to measure the instantaneous wheel slip. The sinkage was measured using ultrasonic sensor. The output voltages from all sensors were recorded using data acquisition card that interfaced with NI-LabView program. 


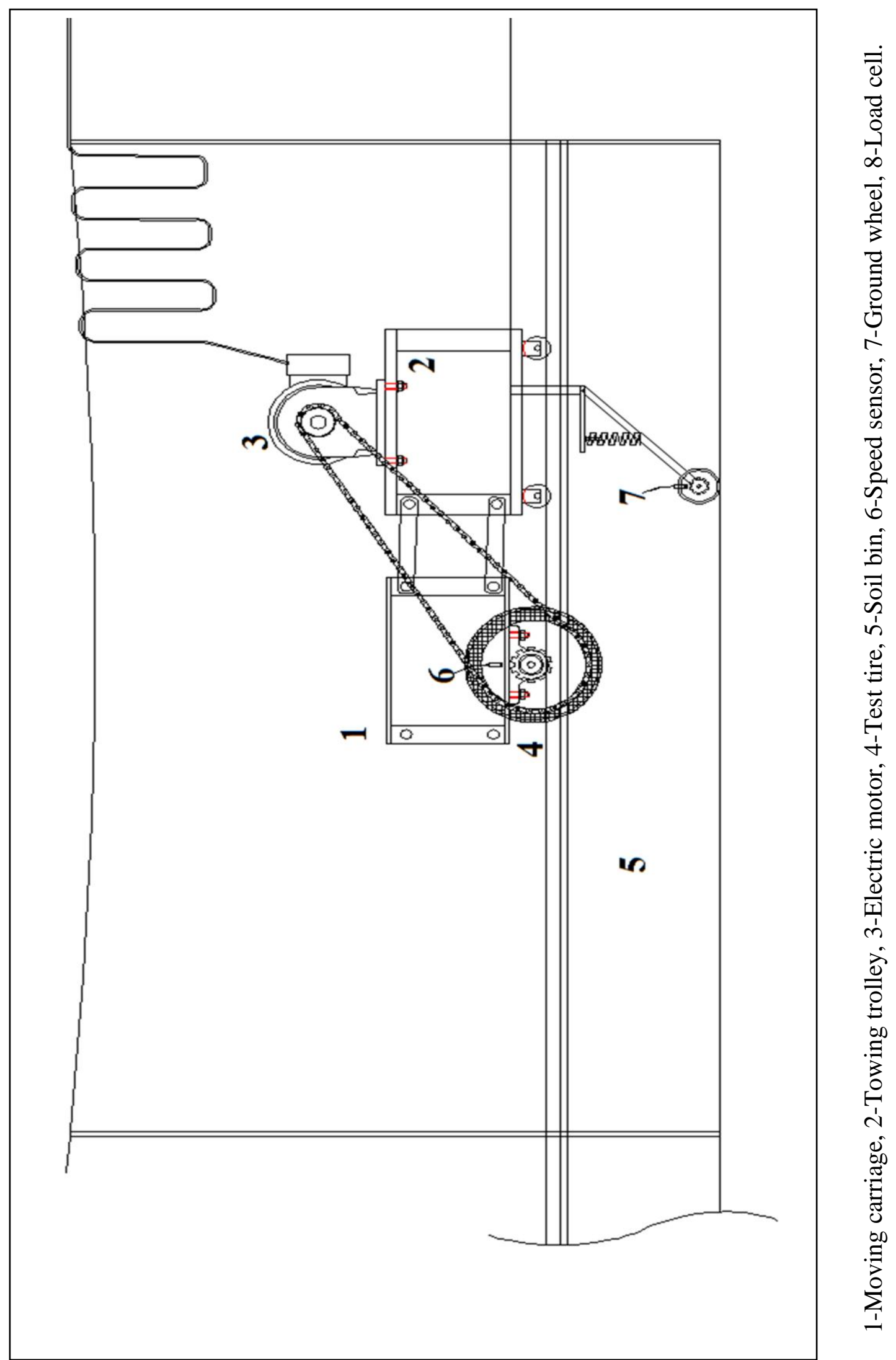

Fig. 2. Test rig schematic 


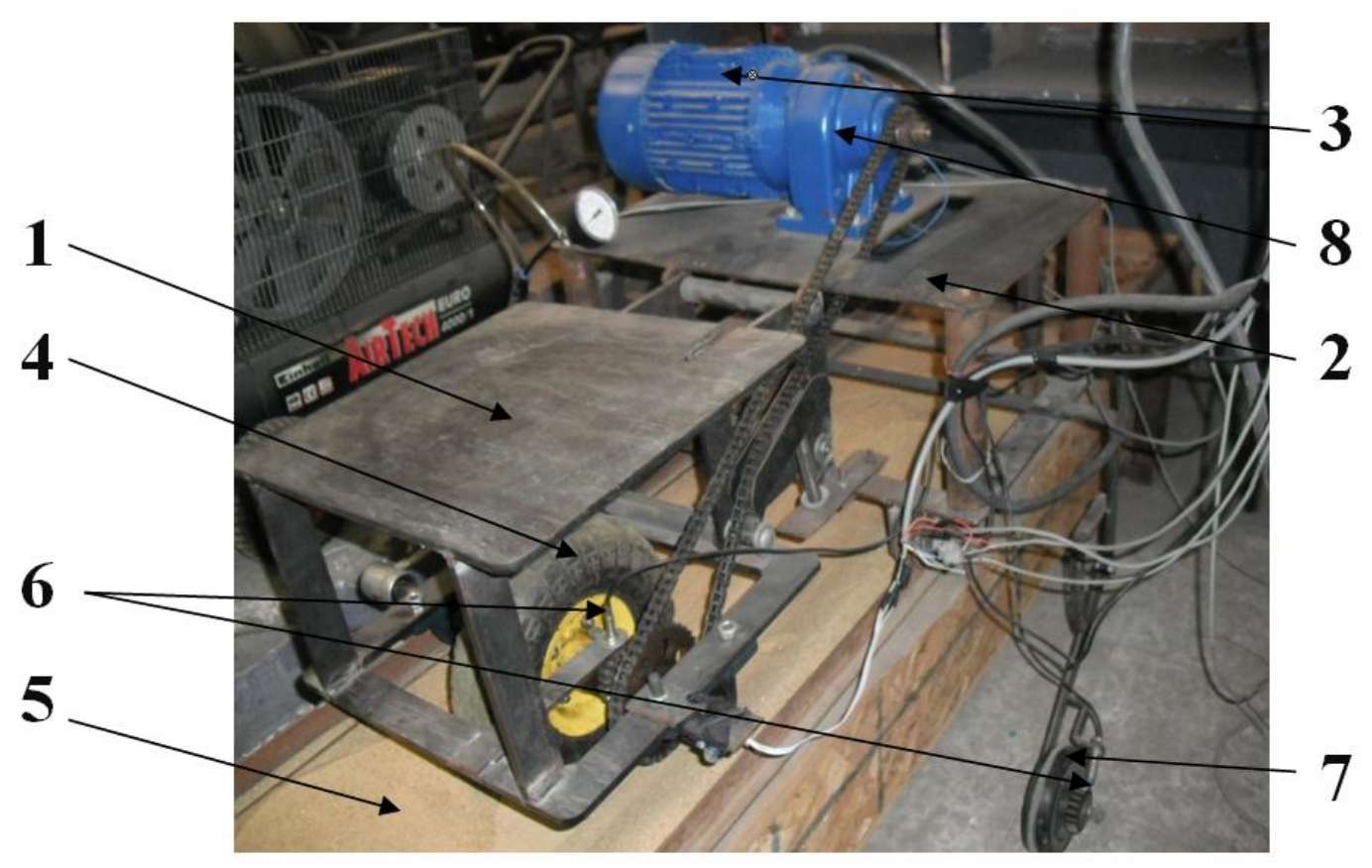

1-Moving carriage, 2-Towing trolley, 3-Electric motor, 4-Test tire, 5-Soil bin, 6-Speed sensor, 7-Ground wheel, 8-Gear Box

\section{Fig. 3. Single wheel tester}

\subsection{Measuring of Wheel Slip}

The measuring two wheel speed sensors were inductive type proximity sensor with a range of $4 \mathrm{~mm}$. using two wheel speed sensors, one was attached with the wheel shaft to measure the theoretical speed and the other was attached with free wheel to measure the actual speed. Both sensors were counted equal signal from equal two toothed gears; one of them was on soil surface Fig. 4-(a) and the other was on the hard surface Fig. 4-(b). The instantaneous wheel slip was calculated using differences in speed sensors using the following formula:

$$
\text { slip }=1-\frac{\text { Actual travel speed }}{\text { Theoretical travel speed }}
$$

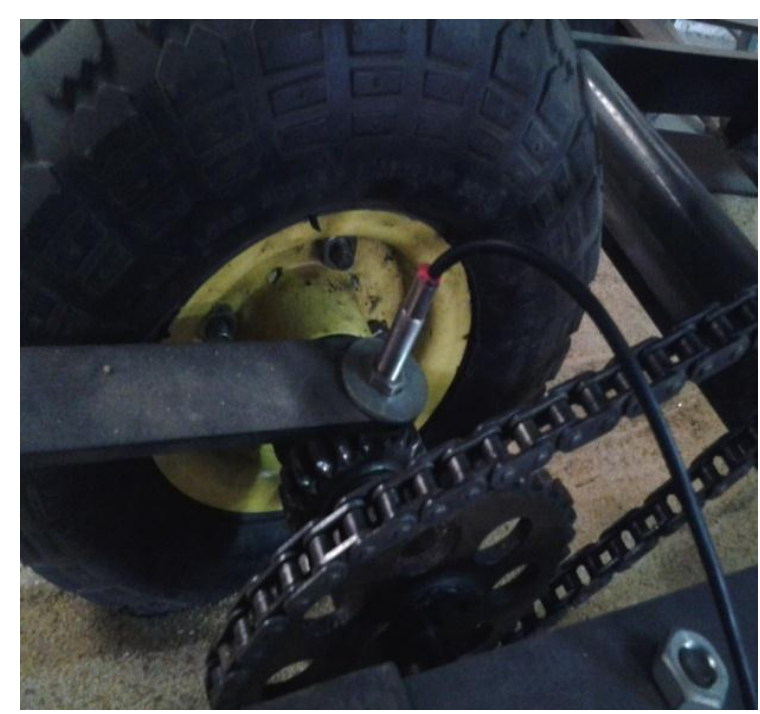

(a) Measuring of theoretical speed

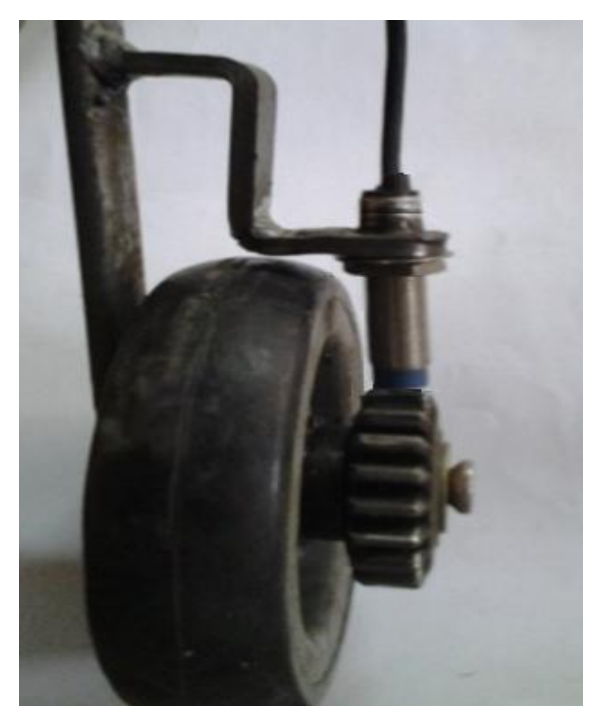

(b) Measuring of actual speed

Fig. 4 Proximity wheel speed sensor 


\subsection{Measuring of Wheel Sinkage}

The instantaneous wheel sinkage was measured using ultrasonic sensor, shown in Fig. 5. It has the advantages of a non-contact distance measurement module. So it is perfect for measuring distance between two moving or non-moving bodies. The ultrasonic sensor measures a range between $3 \mathrm{~cm}$ to $4 \mathrm{~m}$ with an input of 5VDC power supply.

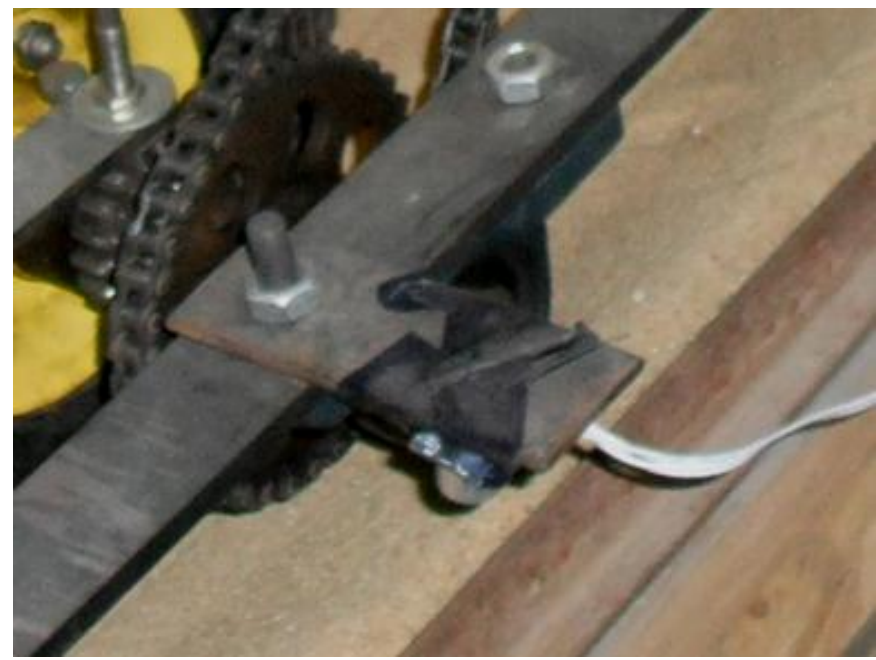

Fig. 5. Ultrasonic distance sensor

\subsection{Measuring of Tire Pressure}

The tire pressure was used to monitor the instantaneous tire pressure. The instantaneous tire pressure was measured using pressure transducer. The transducer type is PA-21G/25 Bar/81388.11. The input power supply is 10 to $24 \mathrm{~V}$ dc and produces current from 4 to $20 \mathrm{~mA}$ according to the pressure change from 0 to 25 bar. So to convert this current to volt a resistance of $980 \mathrm{Ohm}$ and applied voltage 10 Volt has been added as shown in Fig. 6. The output volt was $3.92 \mathrm{~V}$ to $19.6 \mathrm{~V}$ as given in equations $2: 4$, corresponding to pressure current 4 to $20 \mathrm{~mA}$.

$$
\begin{gathered}
V_{\text {min }}=0.004 * 980=3.92 \mathrm{~V} \\
V_{\text {max }}=0.020 * 980=19.6 \mathrm{~V}
\end{gathered}
$$
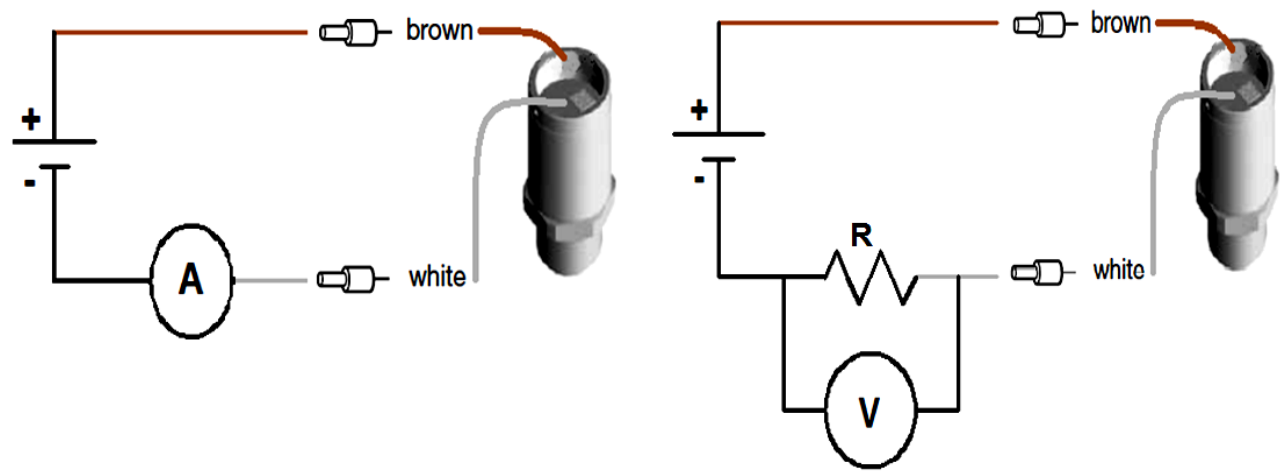

Fig. 6. Pressure sensor circuit

\subsection{Data Acquisition Card (NI USB-6211)}

The output signals from all sensors were recorded using data acquisition card type NI-6211 that interfaced with LabView using USB for high mobility. The data acquisition card includes 16-Bit, $250 \mathrm{kS} / \mathrm{s}$ M Series with 16 analog inputs (16-bit, $250 \mathrm{kS} / \mathrm{s}$ ), 4 digital inputs, 4 digital outputs and 32-bit counters. 


\section{Theoretical Tire Pressure Control}

To control the instantaneous tire pressure, a control system was developed. The control system has a pneumatic circuit. This circuit has been designed and assembled to enable inflating and deflating the tire. The main parts of the pneumatic circuit are; an air compressor with maximum air pressure of 10 bar, directional control valve with double controlled solenoid, variable pressure regulator, pressure gauges, variable non-return throttle valve, and silencers. The control circuit is shown in Fig. 7

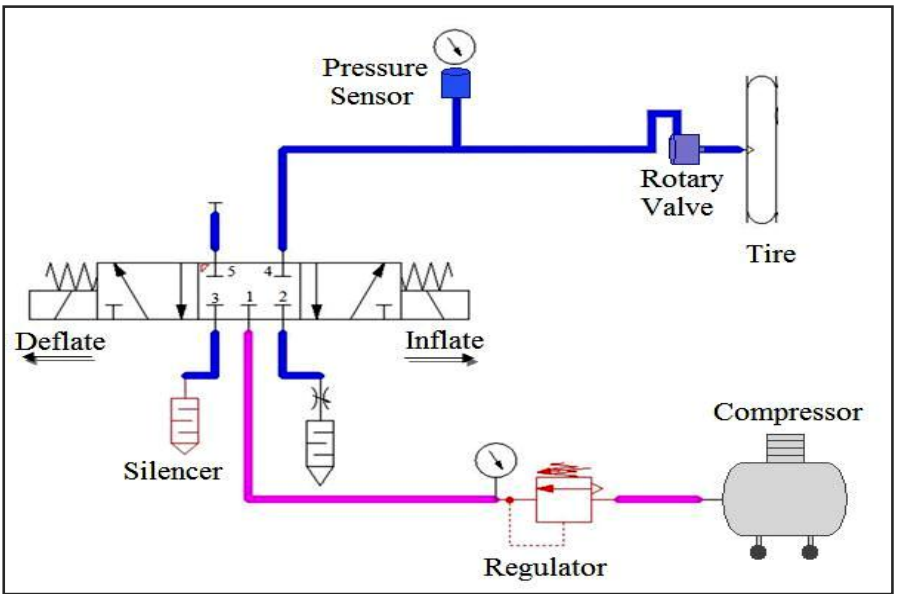

(a) Middle position (Normally closed)

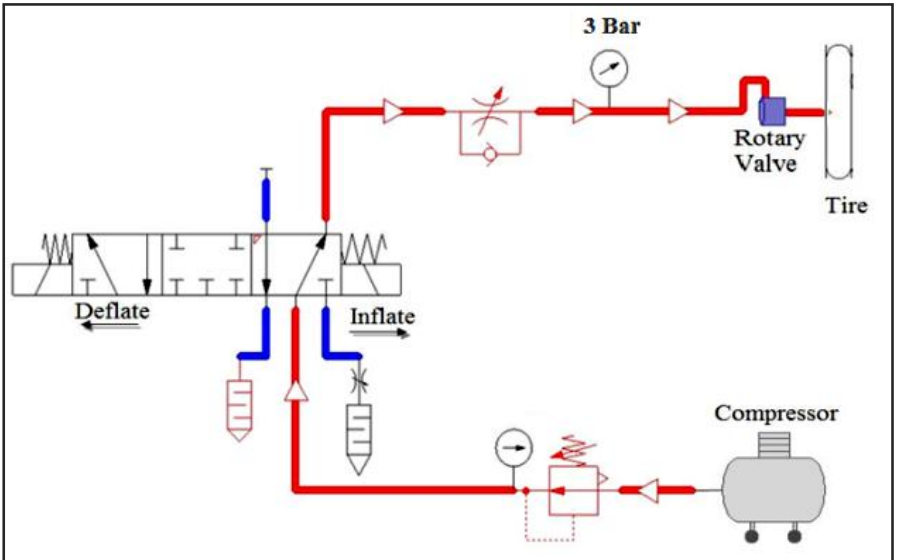

(b) Right solenoid position (Tire Inflate)

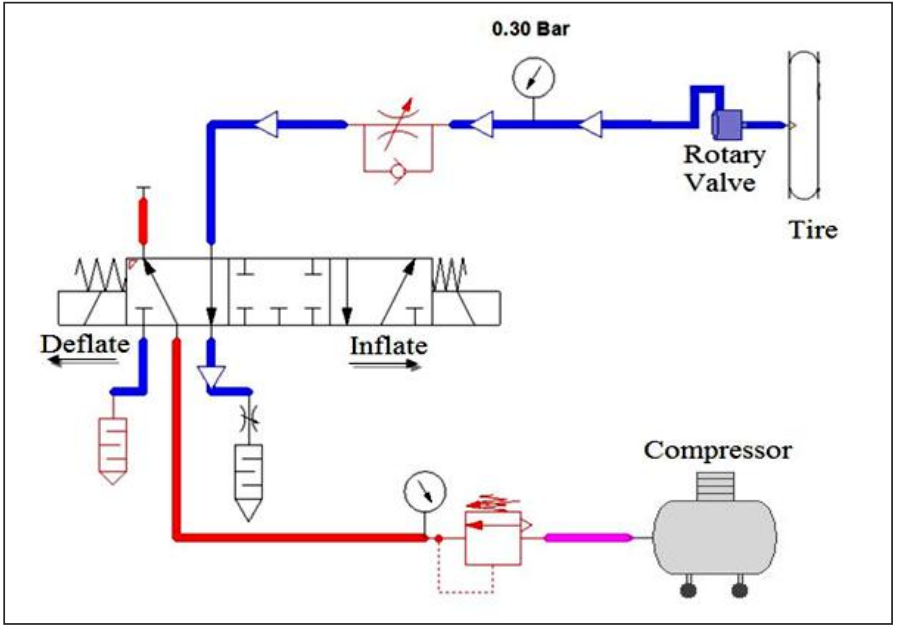

(a) Left solenoid position (Tire deflate)

Fig. 7. Pneumatic cycle 


\subsection{Directional Control Valve (5/3)}

The directional control valve is shown in Fig. 8. It has five ports and two positions changed with two Electrical solenoids for right/left positions, by permanent signal spring return to middle position. Middle position normally closed. The nominal voltage is $10 \div 30 \mathrm{VDC}$, the operating pressure range $2 \div 20$ bar.

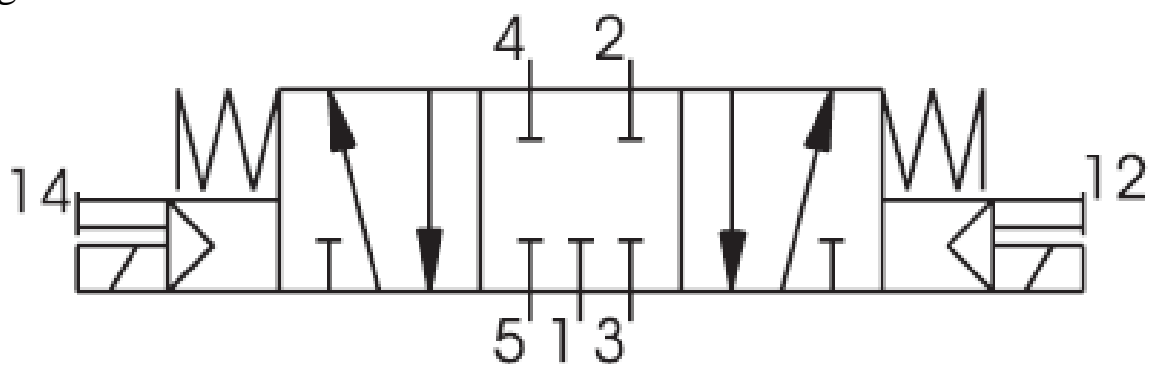

Fig. 8. Directional control valve (pilot operation)

\subsection{Rotary Valve}

The rotary sealed valve shown in Fig. 9

Fig. 9enables control the tire pressure during tire rotation through a hole in the rotating shaft. So it allows inflating / deflating during motion.

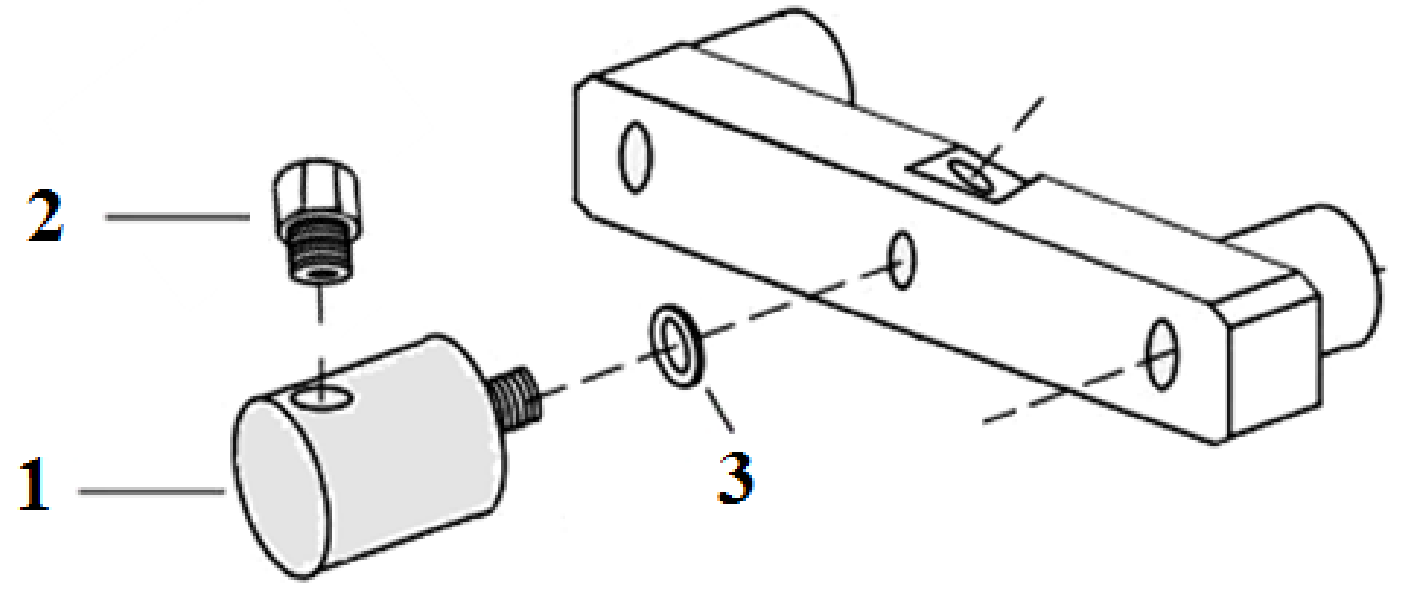

1-rotary valve, 2-fast connection, 3-sealing washer

Fig. 9. Rotary valve construction

\section{Experimental Testing}

\subsection{Measuring of Wheel Slip}

The tested tire size is $4.1-3.5$ at pressure 1.25 bar with vertical load was installed on the single wheel tester. Using the soft dry sand and hard surface in soil bin and by adjusting the tested speed via inverter controller to be $0.325 \mathrm{~m} / \mathrm{sec}$ on sand and $0.25 \mathrm{~m} / \mathrm{sec}$ on hard surface. The variation of wheel revolution per minute was evaluated on both surfaces as shown in Fig. 10, the variation of instantaneous wheel slip was evaluated on both surfaces shown in Fig. 11. 


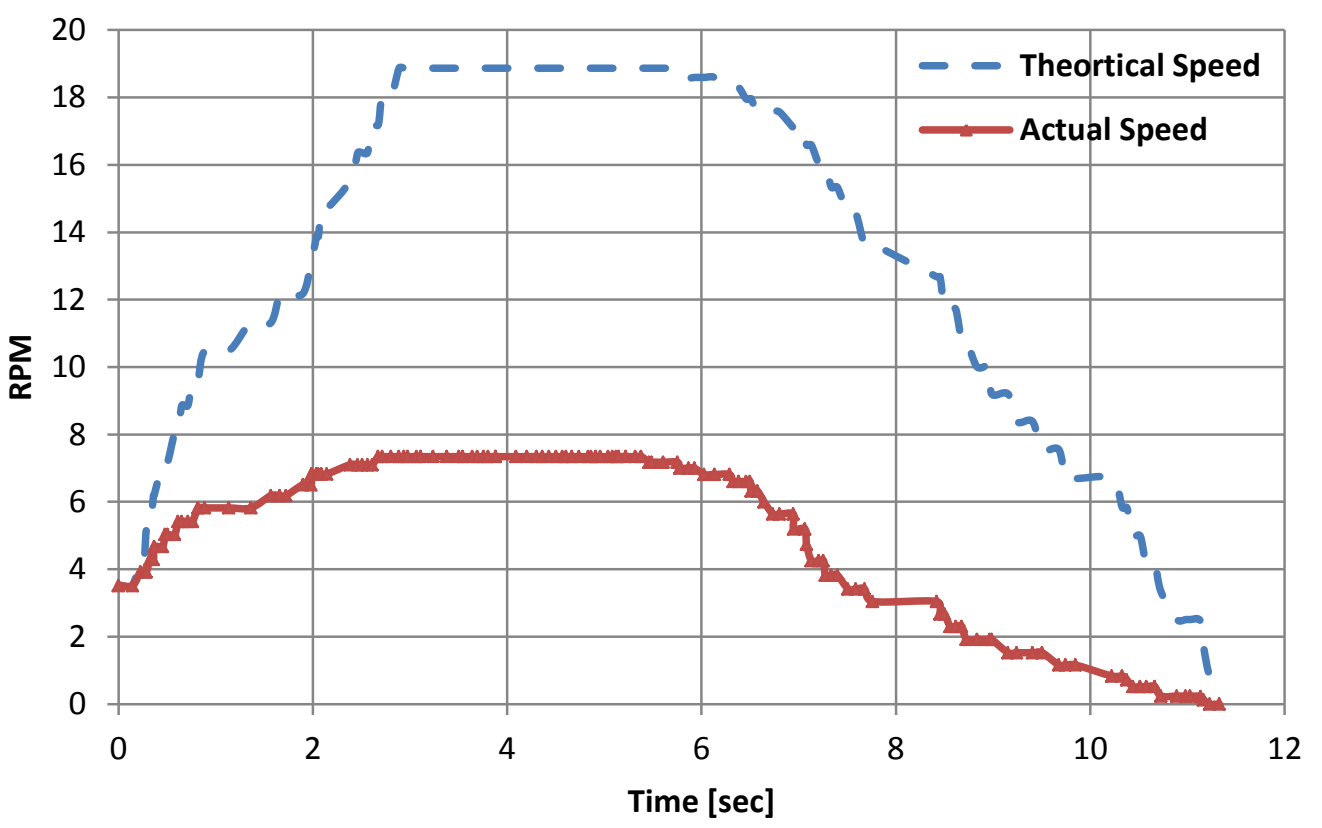

(a) Soft soil

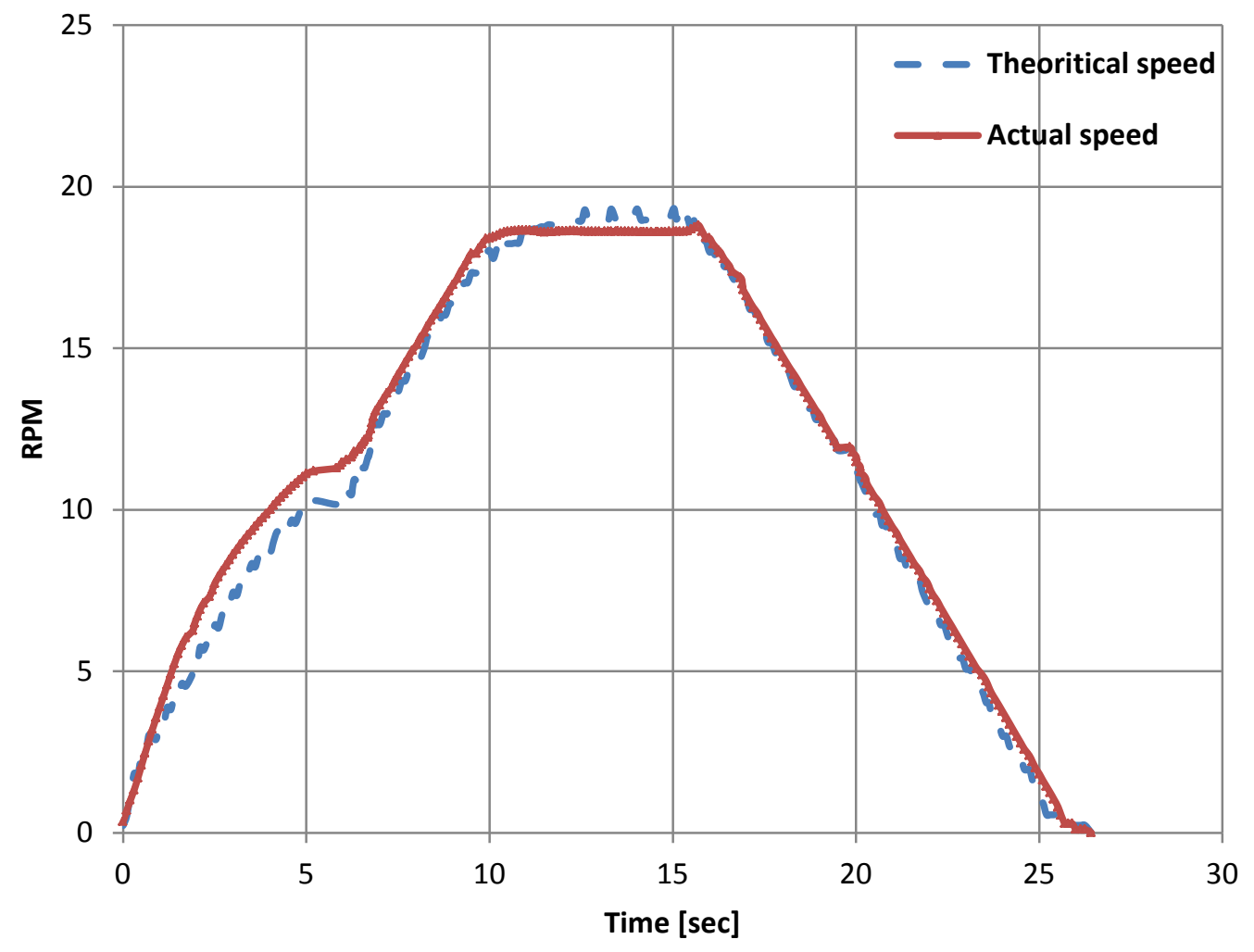

(b) Hard surface

Fig. 10. Variation of theoretical and actual speed with time 


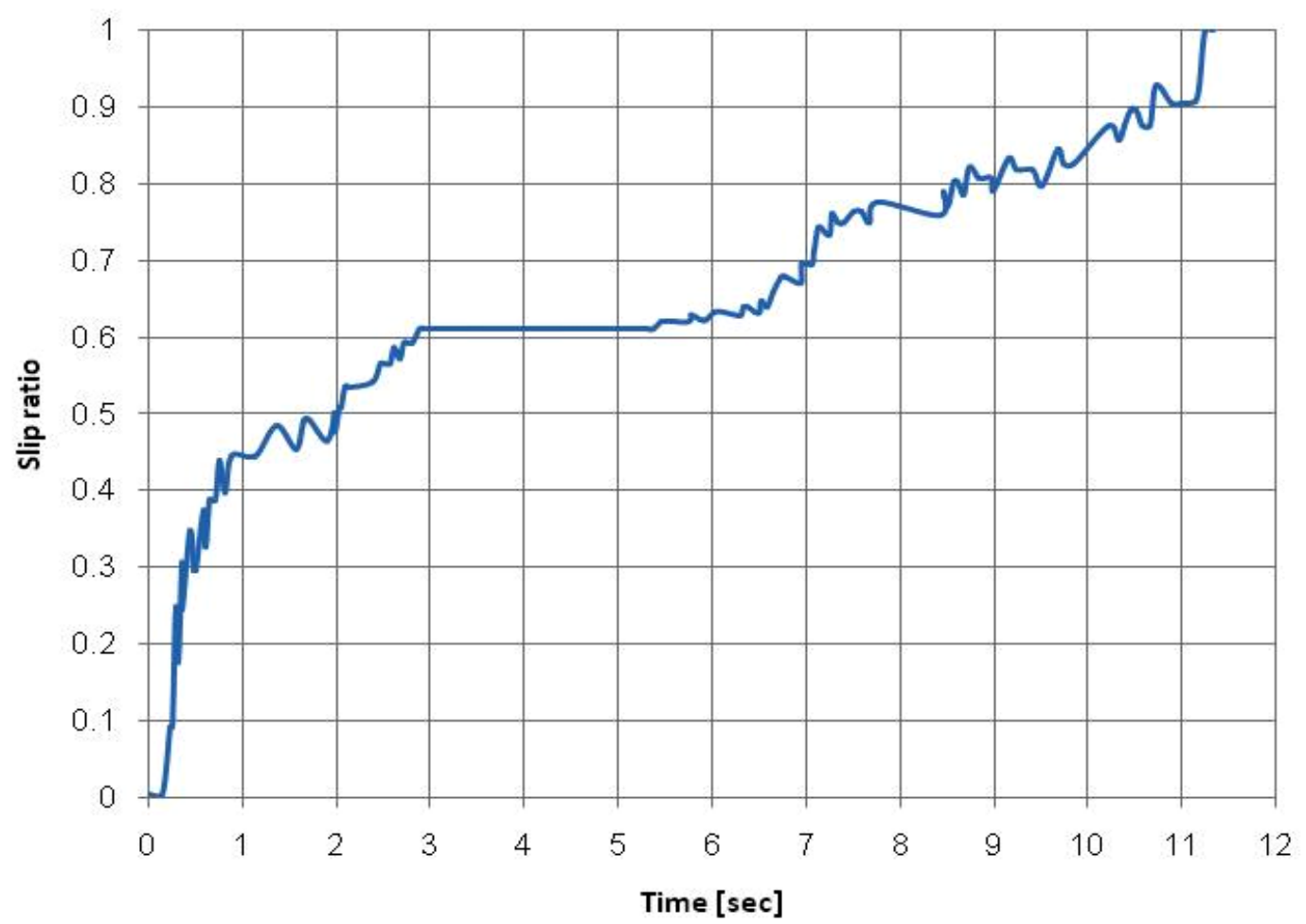

(a) Soft soil

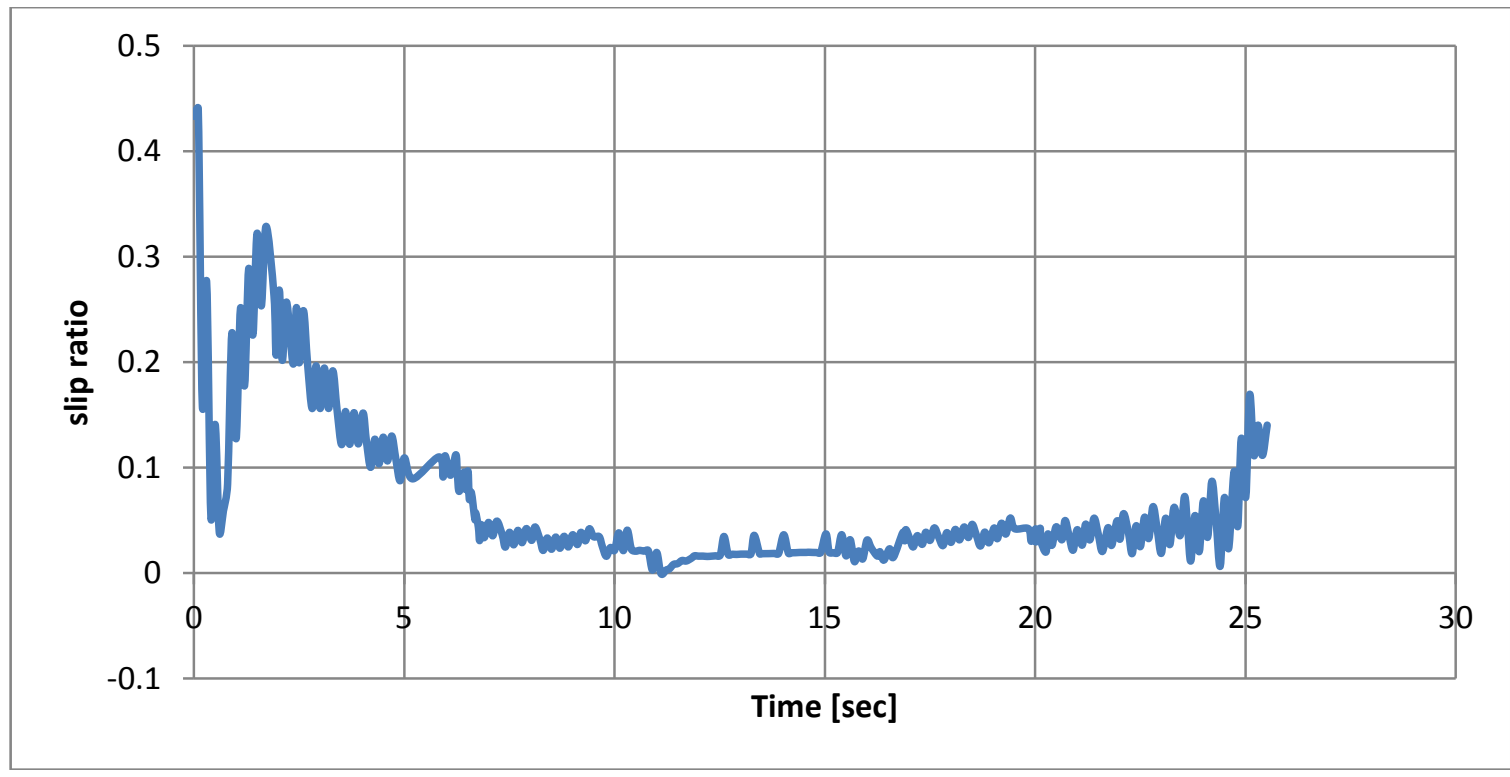

(b) Hard surface

Fig. 11. Variation of slip ratio with time

\subsection{Measuring of Wheel Sinkage}

Using the dry sand in soil bin and by adjusting the tested speed via controller to be 0.325 $\mathrm{m} / \mathrm{sec}$. the variation of instantaneous wheel sinkage was measured as shown in Fig. 12. At the starting of test (transient condition), the tire sinks due to load and soil resistance. 


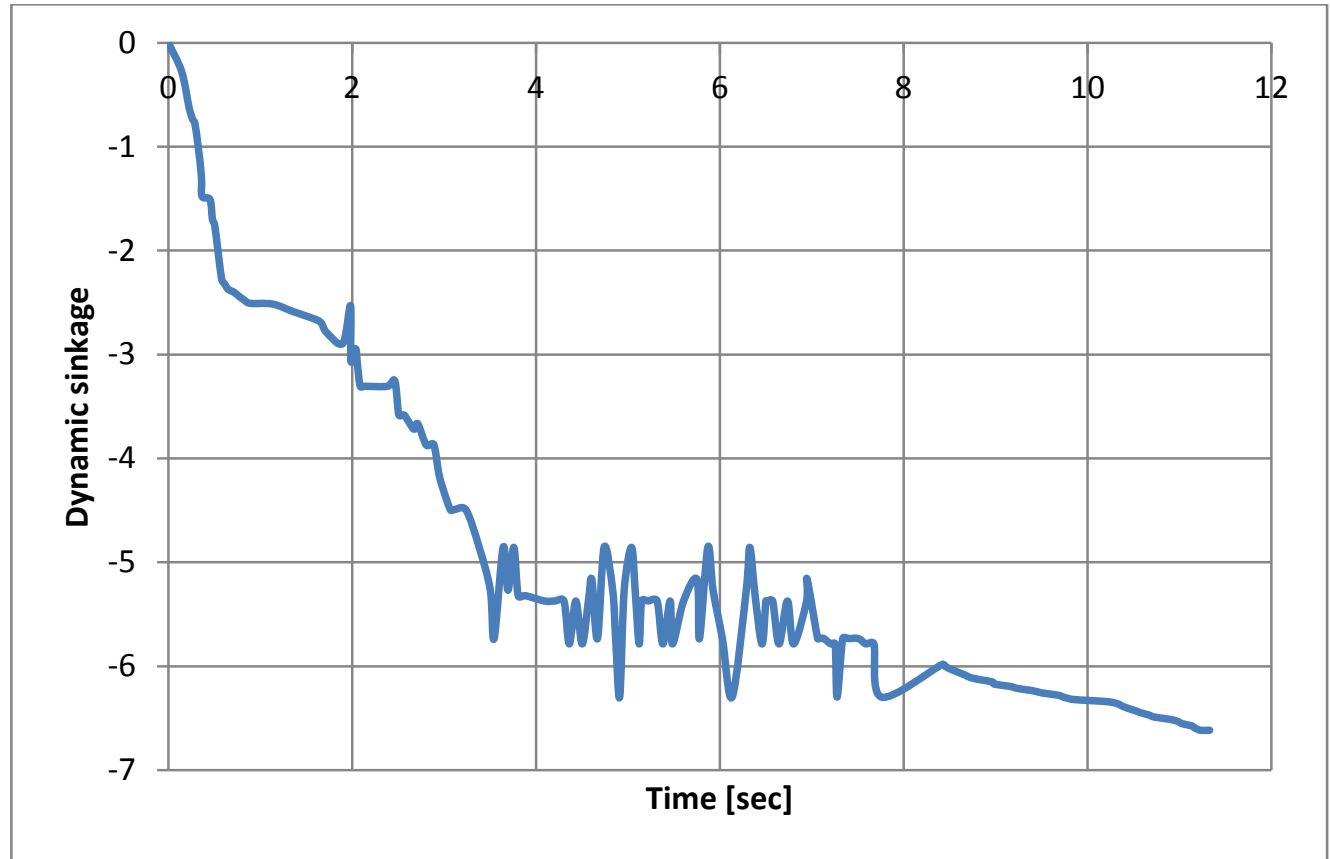

Fig. 12. Variation of dynamic sinkage with time

\subsection{Theoretical Control of Tire Pressure}

The actual speeds have been recorded. The actual speed was measured by free wheel on hard surface. The theoretical speed was measured directly from driving wheel (tire). Using signals from the two speed sensors leads to calculate the slip by using LabView program to manage the sensors, record the data and take a decision of control signal. The proposed flow chart displays the instantaneous wheel slip calculation as shown in Fig. 13. The control panel interface with LabView with all sensors is shown in Fig. 13.

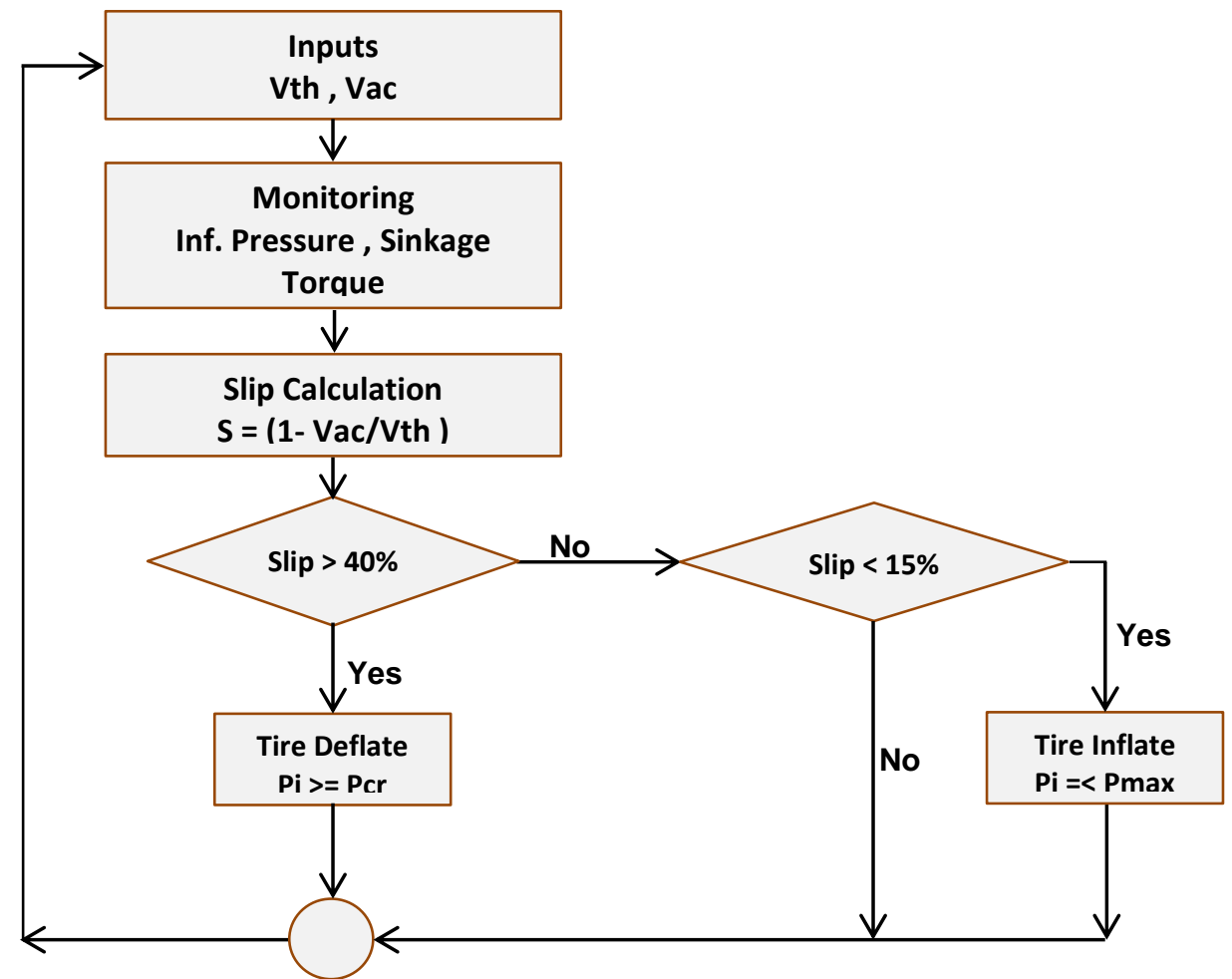

Fig. 14. Control sequence diagram 


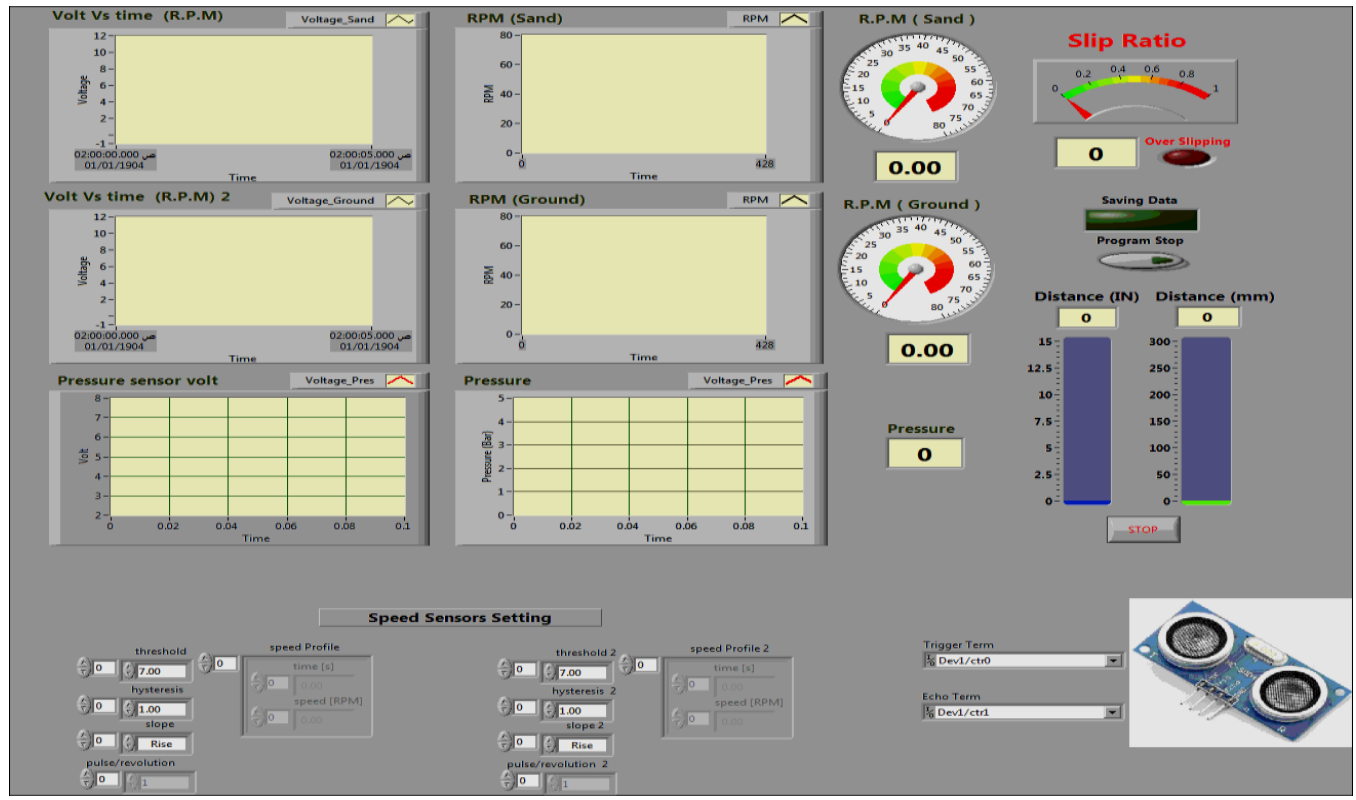

Fig. 15. Control panel Interface with LabView with all sensors

\section{Conclusions}

A scaled soil bin was designed and established. Electro pneumatic control system facilitates tire pressure adaptation. The tester gives continuous monitoring and recording for the forward output speed, calculated slip, tire pressure and dynamic sinkage.

In single wheel tester; the instantaneous wheel speed representing the theoretical speed and free wheel speed representing the actual speed are both measured and recorded. The dynamic sinkage on soft soil due to wheel motion is measured using ultrasonic sensor. A theoretical control algorithm is developed and implemented to control the tire inflation/deflation based on the wheel slip ratio and dynamic sinkage.

\section{References}

[1] Zoz, F. and Grisso, R.D. "Traction and Tractor Performance". Agricultural Equipment Technology Conference. ASAE Publication Number 913C0403. Louisville, KY. 2003

[2] Upadhyaya, S.K., Mehkschau, J., Wulfson, D. and Glancey, J.L. "Development of a unique mobile single wheel testing device". Trans. ASAE 29(5):1243-1246. 1986.

[3] Onwualu, A.P. and Watts, K.C. 1989. "Development of a soil bin test facility". ASAE Paper No. 89-1106, ASAE, St. Joseph, MI.

[4] Wismer, R.D. and Luth, H.J. "Off-road traction prediction for wheeled vehicles". Trans. ASAE 17(1):8-14. 1974.

[5] Wood, R.K. and Wells, L.G. "A soil bin to study compaction". ASAE Paper No. 831044. ASAE, St. Joseph, MI. 1983.

[6] Naderi-Boldaji M., Alimardani R., Sharifi A. and Tabatabaeefar A., "Economical handpushed digital cone penetrometer". Int. Agrophysics, 23, 55-60. 2009.

[7] Niles Road, St. Joseph, Michigan, "Advances in soil bin dynamics". American Society of Agricultural Engineering, ASAE, 2950 USA, vol. 1; 1994.

[8] A.Yahya, M. Zohadie, D. Ahmad, A.K. Elwaleed, A.F. Kheiralla. "UPM indoor tyre traction testing facility". Journal of Terramechanics 44 (2007) 293-301

[9] A. Hendy, S. Hegazy, A. Abdel-Bary, M. A. Emam and Y. Hendawy. "Prediction of wheel numeric for sandy-tire". $15^{\text {th }}$ International conference on applied mechanics \& mechanical engineering. MTC. Cairo. May,2012 